\title{
Putting the Organic Label in Context: \\ Examining the Interactions between the Organic Label, Product Type, and Retail Outlet
}

\begin{abstract}
:
The organic label has been studied extensively in the literature; however, few studies take into consideration the context in which the organic purchase takes place. In this study, we examine the product type (virtue vs. vice) as well as the purchase context (retailer: Target vs. Walmart). Using an online experiment with U.S. consumers $(\mathrm{N}=605)$, we determine how the organic label interacts with each of these contexts and how these interactions impact downstream evaluations such as expected taste, nutrition, safety, likelihood of purchase, and attitude and trust toward the product's brand. Results of the study reveal both the organic label and retail context impact product evaluations. First, results showed organic products were perceived more favorably on a number of measures (including nutrition, safety, brand attitude, and brand trust) than their non-organic counterparts, providing evidence of an organic "halo" effect. Interestingly, though, the organic "halo" did not extend to two measures: expected taste and likelihood of purchase. Secondly, organic labeling benefits virtue and vice products in distinct aspects - the organic virtue product had better expected taste while the organic vice product had higher expected nutrition. Finally, we find that retailers are a crucial factor that moderates the evaluation of organic products. Our results suggest retailers like Target may be better outlets for promoting organic vice products whereas retailers like Walmart may only be good outlets for promoting organic virtue products. This study has important implications for the National Organic Program, the Organic Trade Association, producers, and food brand managers.
\end{abstract}

Key Words: Organic; Retail environment; Consumer perceptions; Brand attitude; Brand trust 


\section{Introduction}

The organic food industry in the United States is a fast-growing segment, with sales expected to reach $\$ 35$ billion in 2014. Sales growth is occurring across multiple product segments, including produce, dairy, meat, grains, snack foods, and even condiments (ERS, 2014). This growth in sales has been accompanied by a growth in the availability of organic products. Traditionally, organic products could only be found at specialty grocers like Whole Foods Market and Sprouts or at local farmer's markets, but consumers now have access to these items at a variety of mainstream grocery retailers (Grgurich, 2012). In 2013, the discount retailer Aldi introduced its SimplyNature brand (which features both organic and natural products) and announced it would offer organic produce in its stores (Durham, 2014; Ewoldt, 2013). In the same year, the U.S. retailer Target (http://target.com) began rolling out its Simply Balanced brand, which boasts many organic products as well as products without genetically-modified ingredients (Tuttle, 2013). Most recently, Walmart (http://walmart.com) joined the organic trend by partnering with Wild Oats to significantly increase its organic offerings in the "pantry" section (Harris and Strom, 2014).

With organic moving more toward the mainstream, there are questions as to how consumers will receive these changes in the marketplace when they are placed in mainstream buying contexts questions that the current literature has yet to address. On the one hand, the presence of more organic foods in large supercenters such as Walmart and Target - which have in excess of 6,000 U.S. retail stores and $\$ 170$ billion in U.S. food sales combined (Target, 2015; Walmart, 2014; Gilyard, 2015) - most likely means more access to organic foods and more affordable prices for consumers. In an interview regarding the new Wild Oats partnership, a Walmart executive noted "We're removing the premium associated with organic groceries" (Harris and Strom, 2014). Thus, organic foods should be more accessible to people of all socio-demographic statuses - a win for 
proponents of more equitable food environments (see Lee, 2013 for a discussion on Los Angeles, CA). Increased availability of organic offerings could also benefit organic producers as higher demand for one's products could lead to gains in economies of scale and/or market share. However, there are others who contend the increased availability of organic may actually be detrimental to the broader brand of "organic" as a label. It has been suggested that organic foods may serve as status symbols and luxury food items for some consumers (Kniazeva and Venkatesh, 2007; van der Veen, 2003). If the price premium is removed, so, too, is the status that accompanies it, which could drive at least some consumers away in search of the next status signaling food (Worstall, 2014). This lack of ability to command premium prices might also disincentivize producers from making organic products (Latacz-Lohmann and Foster, 1997).

The purpose of this paper is to take a closer look at the organic label in context. More specifically, we consider the label in contexts that have preexisting associations, specifically, the product context (the type of product that carries the organic label - virtue vs. vice, in this case) as well as the retail purchase context (the retail outlet where the purchase takes place). We will determine how the organic label interacts with these everyday purchase contexts in the U.S. market and how these interactions impact downstream evaluations, including expected taste, nutrition (healthfulness), safety, purchase likelihood, expected cost, and attitude and trust toward the product's brand.

From a policy standpoint, it is important to understand how consumers evaluate and purchase brands with organic labels when the product type and specific retail context are considered. If organic perceptions vary across product types or retail outlets, this could be problematic for the fast-growing organic segment. To illustrate, the United States Department of Agriculture (USDA) National Organic Program guidelines are the same regardless of where a 
product is sold, such that organic spinach sold in Target would meet the same requirements as organic spinach sold in Walmart or Whole Foods ${ }^{1}$ (USDA, 2011). However, if consumers perceive that products sold at these different stores have differing levels of quality, this would mean: (1) more educational efforts are needed on the part of the National Organic Program (NOP), and (2) organic producers might need to be more selective when choosing a retail partner for distribution. Further, previous research has shown the organic label may not be received as well on some product categories relative to others (Lee, et al., 2013; van Doorn and Verhoef, 2011), particularly in terms of expected taste. Thus, the placement of the organic label on some product types (for instance, products like sodas, cookies, etc.), or coupled with incongruent retail outlets, may actually weaken the broader organic brand, which is a problem for the NOP and organic producers alike. This study aims to provide more insight on the nature of these interactions and consider the implications for producers, consumers and intermediary stakeholders in the organic industry going forward.

\section{Literature Review}

Since its implementation in 2002, The United States Department of Agriculture (USDA) organic label has received substantial attention in the media, in retail food outlets, and in academic research. Much of the current research has focused on answering two key questions: (1) How do consumers perceive foods labeled as organic?; and (2) How much are consumers willing to pay for products labeled as organic?

The most common consumer perceptions of organic labeled foods are related to health and environmental impact. Numerous studies note consumers expect foods labeled as organic to be healthier for them (see Yiridoe, Bonti-Ankomah, and Martin, 2005; Hughner et al., 2007 for

\footnotetext{
${ }^{1}$ It is possible that specific retailers could impose additional standards on suppliers (such as fair wages for workers), but the USDA organic labeling standards themselves would not vary across retailers.
} 
reviews of earlier studies; Roitner-Schobesberger et al., 2008; Olesen et al., 2010; Abrams, Meyers, and Irani, 2010). Lee et al. (2013) performed a more in-depth examination of perceptions of healthfulness and found that consumers tasting products (in this case, cookies, chips, and yogurt) that were labeled organic perceived the organic products as being lower in fat, lower in calories, having more fiber, and more nutritious overall relative to their non-organic counterparts. Schuldt and Schwarz (2010) found the "organic = healthy" association holds even for unhealthy vice products (chocolate chip cookies and ice cream), such that study participants found it more acceptable to skip exercise after eating an organic dessert compared to a conventional dessert.

Organic products are also perceived to be more environmentally friendly than conventional products (Yiridoe, Bonti-Ankomah, and Martin, 2005; Hughner et al., 2007); yet, the literature reveals there is confusion about the specific environmental benefits/regulations related to organic production. Most confusing to consumers seems to be which (if any) pesticides/herbicides/fertilizers can be used in organic farming and whether genetically modified organisms (GMOs) are permissible in organic agriculture (Conner and Christy, 2004; Yiridoe, Bonti-Ankomah, and Martin, 2005; Roitner-Schobesberger et al., 2008).

In addition to health and environmental benefits, consumers perceive organic products to taste better and be safer to consume (Yiridoe, Bonti-Ankomah, and Martin, 2005; Hughner et al., 2007); however, there are a few notable exceptions. A study by Schuldt and Hannahan (2013) found consumers who have lower levels of environmental concern perceive organic foods to be less tasty. In addition, Lee et al. (2013) and van Doorn and Verhoef (2011) found organic "vice" products (such as sodas, cookies) were perceived as less tasty than their non-organic counterparts.

The large majority of findings (see Yiridoe, Bonti-Ankomah, and Martin, 2005; Hughner et al., 2007 for reviews) about how consumers perceive the organic label are positive (creating an 
organic "halo" effect), which suggests products carrying the organic label can demand a price premium in the marketplace compared to conventional products. Numerous studies have identified that consumers are willing to pay more for a variety of organic products. Percent premiums vary widely by study and product. In their review of the organic literature, Yiridoe, Bonti-Ankomah, and Martin (2005) noted most consumers were willing to pay a premium of $10-20 \%$ for products labeled as organic. More recent studies consider the effects of organic labeling on specific products such as apples, chocolate, and meat products rather than all products as a whole. For specific product types, willingness to pay appears to be higher for more perishable, less processed organic products such as fruits and vegetables, meats, and milk (Yiridoe, Bonti-Ankomah, and Martin, 2005; Gil, Gracia, and Sanchez, 2000). Interestingly, Batte et al. (2007) found products do not even need to be $100 \%$ organic for consumers to pay a premium. Thus, it is evident the organic label is valued by consumers in the marketplace.

While the organic literature has grown to be quite extensive, gaps in the knowledge remain. A primary weakness of the current literature is that many studies examine organic in very general terms (e.g., how much more would you pay for organic food?). As noted above, there is research that focuses on specific product types, but few studies actually compare products simultaneously. Further, an even narrower sample of studies has considered consumers' attitudes toward non-fresh (non-produce or non-meat) organic products. Batte et al. (2007) and Gil, Gracia, and Sanchez (2000) examine willingness to pay for a more processed product, cereal, and found that the premiums are lower for these products; however, while it is processed, an organic cereal may still be more in line with expectations of an organic type of food from a consumer point of view compared to a food like a chocolate cookie, for example. This may be because the health associations of "organic" are more congruent with the idea of a 'virtue' food product (Wertenbroch, 
1998) whereas 'vice' food products are more processed and less healthy and therefore may be less congruent with those associations.

A second key limitation to the current organic literature is that few studies, to our knowledge, have considered the retail context (specific retailers) in which organic products are actually purchased. Retailers, such as grocery stores and "big box" stores, carry many different types of food products within their stores; however, each retailer has its own brand image and associations, which can lead to differing perceptions of the products carried in the store. In fact, retailers themselves spent more than $\$ 16$ billion on advertising in 2013 (eMarketer, 2014). Lee and Hyman (2008) classified retail stores as either hedonic or functional - just as products can be classified as hedonic or functional. According to Baker et al. (1992), "hedonic stores generally differ from functional stores in terms of their atmosphere, floor layout, and shoppers' motivations". Childers et al. (2001) note that hedonic stores are characterized by a high-quality and status orientation, an exciting and multisensory design, and have a capacity for "wandering around pleasure". Functional stores, conversely, have a value and convenience orientation, a busy and indifferent atmosphere, and a more modest and austere image. Among food retailers, Whole Foods could be classified as a hedonic store, while Walmart, portrayed as a discount (or value) store, exemplifies a more functional store. Consumers often evaluate a product based on the consistency between its category classification and the store image classification, such that a hedonic product sold in a hedonic (functional) store will be considered more (less) typical and congruent (Lee and Hyman, 2008). In this sense, if an organic ice cream would be considered 'hedonic', then consumers would probably be less likely to evaluate organic ice cream as similar to Walmart's image. 
Though the literature is limited, a few studies exist which discuss the types of retail outlets where organic products are sold. Latacz-Lohmann and Foster (1997) and Ngobo (2011) note that consumers (in Germany and France, respectively) may not associate organic products with conventional supermarkets. One explanation for this could be the inconsistency between store image and product type. Ngobo and Jean (2012) found that a low-price store image decreases the rate of organic purchases. Henryks and Pearson (2011) also note consumers may not associate organic with conventional supermarkets because large organic offerings do not exist in these types of retail outlets (based on qualitative interviews with Australian consumers). Rather, consumers are more likely to shop for organic products at smaller food co-ops or farmers markets (Henryks and Pearson, 2011). These studies lend support to the idea that the retail environment could influence the evaluation (and subsequent purchase) of organic products. In this study, we more directly assess these effects by asking participants to evaluate different product types in the context of specific retail outlets (e.g., using specific store names).

A final limitation of the organic literature is that few, if any, studies have considered that the organic label may not just affect the perceptions of the product but also the brand offering the product. Consumers' brand perceptions and associations affect brand equity (Aaker, 1991), so the organic label could affect brand equity through consumer perception of the label on specific branded products. It is important to understand whether consumers actually find brands that have organic labeled products to be more trustworthy, and whether they have a positive attitude toward brands with organic labeled products. It is also key to identify whether these evaluations are malleable depending on contextual factors such as product type and retail setting. From a producer or manufacturer standpoint, these are important questions to ask, yet research thus far has focused 
on more basic product evaluations such as taste, perceived nutrition, and prosocial benefits (Lee et al., 2013; Schuldt and Hannahan, 2013; van Doorn and Verhoef, 2011; Schuldt and Schwarz, 2010). In this study, rather than asking about products in general, we evaluate consumers' responses to specific products that are also shown as being offered by a specific brand. We opted to use a mock brand rather than an existing brand because past research has shown that strong prior brand knowledge and attitudes are robust against various manipulations used to alter brand attitude/trust (Machleit and Wilson, 1988; Alba, Hutchinson, and Lynch, 1991; Schaefer et al., 2006). Accordingly, all products in our study carried the same mock brand for consistency purposes. Since we chose a fictitious brand, Cam's, with which consumers are not familiar, they will likely look for heuristics to help in their evaluation of the product brand (Nelson, 1970; Rao and Monroe, 1988). One likely heuristic will be the organic label. Moreover, consumers may also rely on the product type and retail store context to guide their evaluations of the unfamiliar

product's brand (Ngobo and Jean, 2012; van Doorn and Verhoef, 2011; Dodds, Monroe, and Grewal, 1991). While past research has largely looked at the more direct effects of an organic label, we are particularly interested in the other factors that may affect actual decision-making and how organic as a label may affect brands. Specifically, we are interested in how the organic label interacts with product type and retail context to impact the product's brand evaluations, especially brand attitude and brand trust.

\section{Data and Methods}

\subsection{Experimental Design}

An online experiment was conducted with 605 U.S. consumers using Amazon's MTurk crowdsourcing system. MTurk samples produce reliable results in line with standard biases in 
decision-making observed in other representative samples (Goodman, Cryder, and Cheema, 2013).

The data produced by MTurk samples have been found to be as reliable as data from traditional polling methods (Buhrmester, Kwang and Gosling, 2011; Simons and Chabris, 2012).

In this study, we utilized a 2 (product type: fresh strawberries vs. chocolate sandwich cookies) by 2 (organic label: USDA organic label present vs. absent) by 2 (retail outlet: Walmart vs. Target) between-subject experimental design, where each participant was randomly assigned to one of the eight study blocks - thus, there were approximately 75 participants per block. Sample product stimuli are provided in figure 1.

While there are many food retailers to potentially use for this study, we opted to use Walmart and Target as our two specific retail environments because (1) both are large retailers with strong awareness and a presence throughout the U.S. ${ }^{2}$ and (2) consumers are increasingly going to "big box" stores to purchase groceries ${ }^{3}$ (O'Conner, 2014). Further, the goal of our design was to select two stores who are similar in food prices yet have distinctly different reputations as retailers in order to determine whether retail environment impacts product evaluations. In terms of food prices, Walmart and Target are quite comparable (relative to comparing Walmart and Whole Foods, for example). Though Walmart is generally known as a discount retailer, comparisons of goods purchased have shown differences as small as \$0.46, with Target actually being less expensive

\footnotetext{
${ }^{2}$ In the U.S., Walmart and Target are two of the leading supercenters (hypermarkets). Walmart is far larger than Target, both in terms of U.S. locations and annual U.S. sales; however, both contain stores in all 50 U.S. states and are widely recognized among U.S. consumers. A market research report shows that Walmart and Target are ranked in the top three U.S. retailers in terms of advertising spending, meaning each store should have its own strong identities or associations with consumers (eMarketer, 2014).

${ }^{3}$ Food sales comprise $56 \%$ of Walmart's annual sales and $21 \%$ of Target's annual sales, and each retailer is working to grow its food retail footprint. Additionally, it is important to note that not all Target stores have a full assortment of groceries. However, Target launched its P-Fresh campaign in 2009, which offers an expanded fresh food layout (including fresh produce and meats) in currently existing Target stores. The P-Fresh format will add $90 \%$ of the food categories available at Super Target stores (Zwiebach, 2009). By the end of 2012, Target projected this expanded layout would be in over 1100 stores (Target, 2012). This figure, in combination with the total number of Super Target stores (250), indicates approximately $75 \%$ of U.S. Target stores have expanded or full food layouts, so it is reasonable to expect study participants can make evaluations about food products sold in Target stores.
} 
(Boyle, 2012). Additionally, both store websites advertise price match policies, indicating each retailer is invested in being competitive on the basis of price. Looking at store reputation, however, Walmart and Target have very different points of emphasis. Walmart is widely acknowledged as having a more utilitarian, functional reputation, with large scale advertising campaigns focused on savings. Conversely, Target stresses style and aspiration, with advertisements that emphasize partnerships with fashion designers and advocate for style in all facets of life (Boyle, 2012). For these reasons, we felt Walmart and Target were good retail candidates for this study.

Upon agreeing to participate in the study using standard IRB protocol, each participant was shown their randomly assigned product/retailer combination (see figure 1) and asked to evaluate the expected taste, nutrition, extent to which the product is safe to consume, likelihood of purchasing the product, and expected product cost. Additionally, participants answered a series of Likert-scale questions regarding their overall attitude toward- and trust of- the hypothetical Cam's brand.

After completing the main measures, participants were asked to provide basic sociodemographic information such as gender, age, income, education, and region of residence. We also asked whether the participant was the primary shopper in the household, how frequently the participant shops in Walmart and Target, where the participant generally purchases groceries (big box store, local/regional supermarket, bulk merchandiser, specialty food store or other), and how often the participant purchases organic food products. Frequency of shopping in Walmart/Target and frequency of purchasing organic food products were controlled in the analyses since they might exert a confounding effect on the dependent measures.

\subsection{Dependent Measures}

\subsubsection{Expected Taste, Nutrition, and Safe to Consume}


For the assigned product block, each participant was asked to rate the expected taste, nutrition (healthfulness), and the extent to which the product is safe to consume on a scale from 1 (tastes very bad, not very healthy, not very safe to consume) to 10 (tastes very good, very healthy, very safe to consume). Similar scales have been used in the literature for taste and nutrition measures (Schuldt and Schwarz, 2010; Schuldt and Hannahan, 2013; Lee et al., 2013).

\subsubsection{Likelihood of Purchase and Expected Product Cost}

Participants were asked to rate the likelihood they would purchase a package of Cam's strawberries (or cookies, depending on the assigned product block) on a scale from 1 (not very likely to buy) to 10 (very likely to buy). In addition, participants were asked how much they would expect the retailer (Walmart or Target) to charge for a package of Cam's strawberries or cookies.

\subsubsection{Brand Attitude and Brand Trust}

To determine attitude toward the Cam's brand, we used a four-item scale following Gardner (1985), Mitchell (1986), and Spears and Singh (2004). Specifically, participants were asked how they would rate the Cam's brand on four dimensions from a scale of 1 (bad, low quality, dislike very much, unappealing) to 7 (good, high quality, like very much, appealing). Trust toward the Cam's brand (Chaudhuri and Holbrook, 2001; Matzler, Grabner-Krauter, and Bidmon, 2008) was also measured using a four-item scale from 1 (not trustworthy, unsafe, unreliable, dishonest) to 7 (trustworthy, safe, reliable, honest). Scale scores were averaged, such that overall attitude and trust scores could range from one (lowest) to seven (highest).

\subsection{Sample Characteristics}


In terms of the demographic profile of our sample, table 1 reveals there was a larger proportion of males $(62.8 \%)$ and younger individuals $(76.2 \%$ of participants were 34 years of age or younger). The majority of participants $(60.8 \%)$ had an annual household income of $\$ 50,000$ or less. Participants were relatively well educated, with $43.8 \%$ indicating they had earned a bachelor's degree or higher, and well dispersed in terms of geographic region.

Looking at shopping behaviors, the majority of participants (73.2\%) were the primary shoppers in their households. The most common grocery shopping destinations for our sample were local or regional grocery stores (55.9\% of participants), followed by Walmart $(20.1 \%)$. In terms of organic shopping behavior, $52.7 \%$ of participants indicated they purchased organic foods at least sometimes. There were no significant differences in participant characteristics across the eight product blocks.

\subsection{Data Analysis}

We conducted 2 (product type: strawberry vs. cookie) x 2 (organic label: organic vs. nonorganic) x 2 (retail outlet: Walmart vs. Target) factorial analyses of variance (ANOVAs) to examine how the three independent variables jointly influence expected taste, nutrition, safety, likelihood of purchase, perceived cost, and brand attitude/trust. If any interaction effects were significant, posthoc independent samples t-tests were conducted to further explore the interactions.

\section{Results}

\subsection{Manipulation Checks}

Manipulation checks were conducted to ensure that (1) the frequency of shopping in Walmart and Target and (2) frequency of organic food purchases were similar across the eight 
conditions so that they would not exert confounding effect on dependent measures. Univariate analyses of variance (ANOVAs) showed no main or interaction effects for frequency of shopping in Walmart $(p s>.20)$ or Target $(p s>.10)$, nor for frequency of purchasing organic food products $(p$ s $>.35)$ or whether the survey respondents were primary shoppers or not $(p s>.25)$, suggesting that these variables were similar in terms of values across all conditions and could not exert confounding effect on dependent measures.

\subsection{Expected Taste}

Results showed that the main effects of product type and retail outlet were significant. Participants rated the expected taste of strawberries $(M=7.62)$ higher than cookies $(M=6.43), F(1$, $597)=66.47, p<.001$. Further, food products sold in Target $(M=7.27)$ had higher expected taste ratings than those sold in Walmart $(M=6.77), F(1,597)=11.81, p=.001$. Interestingly, in contrast to past research, organic labeling had no overall main effect on expected taste, $F(1,597)=.97, p=$ .33 .

A marginally significant two-way interaction between product type and organic labeling was observed (see figure 2$), F(1,597)=3.16, p=.07$. Specifically, organic strawberries $(M=7.81)$ had a higher expected taste rating than non-organic strawberries $(M=7.41), t(301)=-2.13, p=.03$. However, organic and non-organic cookies $(M=6.38$ and 6.49 , respectively) had similar expected taste ratings, $t(300)=.50, p=.62$.

A significant three-way interaction was also observed (see figure 3 ), $F(1,597)=4.03, p=$ .045. Specifically, organic strawberries sold in Walmart $(M=7.68)$ had a higher expected taste rating than their non-organic counterparts $(M=7.00), t(150)=-2.53, p=.01$. However, there was no significant difference in expected taste ratings for organic and non-organic strawberries sold in 
Target $(M=7.95$ and 7.83 , respectively), $t(149)=-.47, p=.64$. Turning to cookies, our analyses revealed expected taste ratings did not differ for organic and non-organic cookies sold in Walmart $(M=6.00$ and 6.41 , respectively), $t(148)=1.24, p=.22$, or Target $(M=6.75$ and 6.57 for organic and non-organic cookies sold in Target, respectively), $t(150)=-.62, p=.54$.

Comparing across stores, we found that organic strawberries and non-organic cookies in both Walmart and Target had similar expected taste ratings, $p$ s $>.10$. However, non-organic strawberries sold in Target $(M=7.83)$ had a higher expected taste rating than those sold in Walmart $(M=7.00), t(150)=-3.22, p=.002$. Similarly, organic cookies sold in Target $(M=6.75)$ had a higher expected taste rating than organic cookies sold in Walmart $(M=6.00), t(149)=-2.31, p=$ .02 . Other interaction effects were non-significant, $p \mathrm{~s}>.10$.

\subsection{Nutrition (Healthfulness)}

Results showed that the main effects of all independent variables were significant. Organic products $(M=6.14)$ were considered more nutritious than their non-organic counterparts $(M=$ 5.03), $F(1,597)=57.27, p<.001$. Strawberries $(M=8.19)$ were considered more nutritious than cookies $(M=2.98), F(1,597)=1283.96, p<.001$. Products sold in Target $(M=5.78)$ were considered more nutritious than those sold in Walmart $(M=5.39), F(1,597)=7.36, p=.007$.

A significant two-way interaction between organic labeling and product type was observed (see figure 4$), F(1,597)=20.81, p<.001$. Specifically, although organic products were universally perceived as more nutritious than were non-organic products, the difference in perceived nutrition between organic and non-organic cookies $(M=3.86$ vs. $2.09 ; t(300)=-7.94, p<.001)$ is larger than that between organic and non-organic strawberries ( 8.41 vs. $7.98 ; t(301)=-2.30, p=.02)$. Other interaction effects were non-significant, $p \mathrm{~s}>.10$. 


\subsection{Safe to Consume}

Results showed that the main effects of all independent variables were significant. Organic products $(M=8.42)$ were considered safer than non-organic counterparts $(M=7.88), F(1,597)=$ 13.91, $p<.001$. Strawberries $(M=8.38)$ were considered safer than cookies $(M=7.92), F(1,597)=$ $10.18, p=.001$. Products sold in Target $(M=8.43)$ were considered safer than those sold in Walmart $(M=7.87), F(1,597)=15.38, p<.001$. No interaction effects were found, $p \mathrm{~s}>.10$.

\subsection{Likelihood of Purchase}

Results showed that the main effects of product type and retail outlet were significant. People were more likely say that they would purchase the strawberries $(M=6.49)$ than cookies $(M$ $=4.29), F(1,597)=114.52, p<.001$. Products sold in Target $(M=5.61)$ were more likely to be purchased than those sold in Walmart $(M=5.17), F(1,597)=4.69, p=.03$. Interestingly, likelihood of purchasing organic and non-organic products did not differ $(M=5.54$ and 5.24, respectively), $F(1,597)=2.06, p=.15$. No interaction effects were found, $p \mathrm{~s}>.10$.

\subsection{Expected Product Cost}

Results showed that the main effects of all independent variables were significant. As shown in previous studies, participants perceived organic products $(M=\$ 4.02)$ as more expensive than their non-organic counterparts $(M=\$ 3.26), F(1,597)=48.16, p<.001$. Strawberries $(M=\$ 3.94)$ were perceived as more expensive than cookies $(M=\$ 3.34), F(1,597)=30.67, p<.001$. Additionally, items sold at Target $(M=\$ 3.81)$ were expected to cost more than those sold at Walmart $(M=\$ 3.47), F(1,597)=9.57, p=.002$. 
A marginally significant interaction effect between organic labeling and product type on expected cost was observed (see figure 5 ), $F(1,597)=3.51, p=.06$. Specifically, the difference in expected cost between non-organic strawberries and cookies $(M=\$ 3.67$ vs. $\$ 2.86 ; t(301)=6.42, p$ $<.001)$ was larger than that between organic strawberries and cookies $(M=\$ 4.21$ vs. $\$ 3.82 ; t(300)$ $=2.21, p=.03)$. Other interaction effects were non-significant, $p \mathrm{~s}>.10$.

\subsection{Attitude towards Cam's Brand}

Results showed that the main effects of all independent variables were significant. Attitude towards the Cam's brand for organic products $(M=5.06)$ was higher than that for non-organic products $(M=4.64), F(1,597)=19.38, p<.001$. Brand attitude was also higher when the product was strawberries $(M=5.33)$ relative to cookies $(M=4.33), F(1,597)=116.05, p<.001$. Further, attitude towards the Cam's brand was higher when the product was sold in Target $(M=4.53)$ as opposed to Walmart $(M=4.19), F(1,597)=8.03, p=.005$. No interaction effects were found, $p$ s $>$ .10 .

\subsection{Trust towards Cam's Brand}

Results demonstrated that the main effects of all independent variables were significant.

Trust towards the Cam's brand for organic products $(M=5.19)$ was higher than that for non-organic products $(M=4.83), F(1,597)=15.80, p<.001$. Higher levels of brand trust were also exhibited when the product was strawberries $(M=5.14)$ as opposed to cookies $(M=4.87), F(1,597)=9.30, p$ $=.002$. In addition, trust towards the Cam's brand was higher when products were sold in Target $(M$ $=5.16)$ relative to when products were sold in Walmart $(M=4.86), F(1,597)=11.81, p=.001$. 
A significant three-way interaction was observed (see figure 6 ), $F(1,597)=3.63, p=.05$. Specifically, for Walmart, brand trust was higher for organic strawberries $(M=5.35)$ than nonorganic strawberries $(M=4.71), t(150)=3.44, p=.001$; however, brand trust was similar for organic and non-organic cookies ( $M=4.81$ and 4.56 , respectively), $t(148)=1.39, p=.17$. However, the opposite pattern occurred for Target, with organic cookies $(M=5.27)$ exhibiting higher levels of brand trust than non-organic cookies $(M=4.84), t(150)=2.47, p=.02$; whereas the organic and non-organic strawberries had similar levels of brand trust $(M=5.32$ and 5.20, respectively), $(149)=$ $.65, p=.52$. Other interaction effects were non-significant, $p \mathrm{~s}>.10$.

\section{Discussion}

The organic label has been examined extensively by academic researchers. Most studies have focused on the potential value of this label (determining whether a premium exists in the marketplace) or how consumers perceive the organic label. However, a weakness of academic research so far has been that most studies examine organic labels in isolation. More recent research has started to observe how the organic label impacts different product types (Lee et al., 2013; van Doorn and Verhoef, 2011); yet few studies have looked at, and no studies that we know of have experimentally assessed, how the retail context in which purchases actually occur can affect organic product perceptions (and the extent of their organic "halos").

The present study contributes to the literature by experimentally examining the organic label in context, both in terms of the product type and the retail outlet. We determine how the organic label interacts with these consumption contexts and how these interactions impact product evaluations, (such as expected taste, nutrition, safety, etc.) as well as how purchase contexts and 
labels might affect the product's brand (including brand attitude and brand trust) for U.S. consumers.

First, all else held constant, products carrying the organic label outperformed their nonorganic counterparts on several measures, including nutrition, safety, brand attitude and brand trust - thus, there is definitely evidence of an organic "halo" effect. Interestingly, though, organic products were not rated significantly different from non-organic products on two measures: taste and likelihood of purchase. Similar to past research (Batte et al., 2007; Gil, Gracia, and Sanchez, 2000), we observed that likelihood of purchasing an organic vice product (chocolate cookie) did not differ from that of purchasing their non-organic counterparts. Interestingly, the likelihood of purchasing a virtue product (strawberries) was similar regardless of whether they were labeled organic or not, which is different from past research findings that organic labeling contributes positively to likelihood of purchase (Yiridoe, Bonti-Ankomah, and Martin, 2005). There are several possible explanations of this result. First, taste is considered to be a key determinant in food selection (Asp, 1999), so a lack of differentiation in taste may help explain the lack of difference in likelihood of purchase. Second, the cost of organic products may also factor in to the purchase likelihood decision. Our results show that organic products were expected to cost significantly more than their non-organic counterparts, which could reduce the likelihood of purchase for priceconscious consumers. Overall, our findings suggest cost and a lack of perception of a taste difference may be two influential factors that deter purchase of organic products regardless of the "halo" effect. Future work should look at whether this was specific to our study or if these may be enduring now that organic is increasingly part of mainstream product offerings.

The main effects of product type and retail outlet were more straightforward relative to the organic main effects. The virtue product (strawberry) dominated the vice product (chocolate 
sandwich cookie) across all measures, and products sold in Target were rated more highly than those sold in Walmart across all measures. Although both products sold in Target were expected to cost significantly more, respondents still expressed higher purchase likelihood for products sold in Target relative to those sold in Walmart. This may be related to the perceptions of taste. Food products from Target were expected to taste better overall compared to food products offered by Walmart. This taste-cost tradeoff may benefit food products at Target. Another explanation for this result could be related to aspects of the differing images of these two retailers. As a check, we measured participants' attitudes and trust toward the retail outlet in their assigned product block in addition to their attitude and trust toward the product's brand (Cam's). Our results show that while participants were more likely to be Walmart shoppers $(20.1 \%$ of respondents primarily shop at Walmart; $4.8 \%$ at Target) in our study, Target still outperformed Walmart in terms of attitude and trust ratings ( $p$ s $<0.001$ ), which may explain why purchase likelihood ratings are higher for Target despite higher expected product costs.

While main effects are important for connecting our work with previous findings, the main focus of our research was on how organic labeling and retail context interact with each other and product type so that we can begin understanding more complex effects that affect everyday buying. When examining the interactions between the organic label and product type, the most notable results were on expected taste and nutrition. Organic strawberries were rated higher on expected taste than non-organic strawberries, yet expected taste was similar between organic and non-organic cookies. Conversely, when looking at nutrition, there was no significant difference between organic and non-organic strawberries, yet organic cookies were rated significantly more nutritious than their non-organic counterparts. Ironically, these findings suggest the purchase of virtue products such as organic strawberries may be based more on taste considerations, while vice products such as 
organic cookies may be based more on nutrition factors. Both the taste and nutrition results are consistent with previous literature regarding virtue and vice products (Wertenbroch, 1998). Specifically, several studies have found that vice products benefit from the organic label in terms of their health or nutrition ratings (Schuldt and Schwarz, 2010; van Doorn and Verhoef, 2011; Lee et al., 2013). Virtue products, on the other hand, are inherently perceived as more healthy (and thus more 'virtuous'), so the organic label might do little to improve this evaluation (i.e., a ceiling effect). Instead, they were considered as more tasty.

Last but not least, our findings suggest that retail outlets are a crucial factor that moderates evaluation of organic products. Results reveal the retail outlet had two moderating effects, one on expected taste and the other on brand trust. With expected taste, our results showed that ratings for strawberries sold in Walmart could be significantly improved if the strawberries carried the organic label. Additionally, when comparing similar products across stores, we found that non-organic strawberries and organic cookies sold in Target were rated significantly higher on expected taste than their Walmart counterparts; organic strawberries and non-organic cookies had similar expected taste ratings across these two retail outlets. This could indicate that virtue products carrying the organic label could overcome some of the negative effects of the retail context. However, organic labeling may actually have increased problems in terms of taste expectations in certain retail contexts. It should be noted that the means for perceived taste for organic strawberries were quite high $($ Walmart $=7.68$, Target $=7.95)$ and therefore it is possible that consumers had reached the high end of what they were willing to rate for expected taste of a product that they could only see, but were still highly familiar with. Such a ceiling effect would prevent us from seeing any additional differences that might exist between retailers on taste perceptions of organic strawberries. Thus, future research should use virtue products that might not have such a high level of expected 
taste (e.g. Brussels sprouts) in order to be able to see if there is a difference, and may also want to specifically look at the role that taste of the nonorganic version of a product might play in how organic labeling can affect taste perceptions.

Turning to brand trust, our results revealed that trust in the fictitious Cam's brand is more variable when its products are sold in Walmart as opposed to Target. However, we again observed that carrying the organic label can significantly improve brand trust for strawberries sold in Walmart. This effect also holds for organic cookies sold in Target. Taken together, these results suggest that a retailer similar to Target may be a better outlet for promoting organic products in general, but especially organic vice products; conversely, retailers like Walmart may only be good outlets for promoting organic virtue products.

\subsection{Implications}

This study has implications for a number of stakeholders, including the United States Department of Agriculture (USDA) National Organic Program (NOP), the Organic Trade Association (OTA), and individual product brand managers. First, for the NOP, the key takeaway from this study is the USDA organic label is not perceived uniformly across product types or retail outlets, even though certified organic strawberries sold in Walmart are held to the same USDA standards as certified organic strawberries sold in Target. Clearly, more processed products may have additional regulations to uphold (related to processing facilities, for example), but the bottom line is that any product carrying the USDA Organic seal is required to contain at least $95 \%$ organic ingredients (USDA, 2011). Unfortunately, consumers do not appear to be aware of this fact. In our

study, we posed an additional inquiry to participants in the organic experimental conditions $(N=$ 301) asking "On a scale from $0 \%$ organic content to $100 \%$ organic content, how much organic 
content do you think Cam's organic strawberries (cookies) contain?" We realize this could be an odd question for strawberries as they are most likely all or none; however, this is a useful question for cookies to determine if consumers are aware of the NOP's 95\% organic threshold. On average, participants believed USDA Organic strawberries contained $84.5 \%$ organic content while USDA Organic cookies contained $62.1 \%$ organic content, a significant difference between product types ( $p$ <.001). While the question did not reference the retailer that they had been shown as offering the Cam's organic product, there was also a significant interaction between store and product type ( $p$ $<.05)$, which was primarily driven by the organic content estimates for cookies. Specifically, Cam's organic cookies at Walmart were estimated to contain $57.9 \%$ organic content whereas at Target Cam's organic cookies were estimated to contain $66.2 \%$ organic content. These results suggest consumers may struggle to understand what the organic label means, particularly for more highlyprocessed food products; further, this lack of clarity may contribute to consumer skepticism toward the organic label and/or dilution of the "organic" brand. Thus, it is important for the NOP to communicate (1) what the organic label means and (2) that the meaning is the same anywhere USDA organic products are sold.

While educational efforts are also important for the Organic Trade Association, this study offers some additional insights to OTA members. With the passage of the Agricultural Act of 2014 (the 2014 Farm Bill), the organic industry was granted the right to establish its own "checkoff" program - a program that would collect a percentage of organic producers' earnings to use for research and promotion of organic foods (Greenaway, 2014). The structure and details of an organic checkoff program are currently being debated, but some producers have suggested different organic commodity groups (for instance, organic dairy group, organic produce group, etc.) should each get their own allocation of checkoff dollars to use as they best see fit (Greenaway, 2014). Findings from 
this study do suggest that the organic label may unevenly benefit some types of products more than others. In fact, some product types may attenuate the organic brand image. Thus, producer groups may want to consider a more disaggregated structure to promote the benefits of their specific product category. Additionally, the OTA may want to evaluate its relationships with retailers and, should a checkoff program be established, allocate some of the checkoff funding to promote the uniform quality of organic products across retail establishments.

Finally, for producers and food brand managers, it is important to understand how consumers evaluate products in context. For many products, adding the organic label will be beneficial; however, the organic label may be inconsistent with some product types (particularly vice products or products perceived as less fresh), and it may be inconsistent with the images of retailers who sell the product. These inconsistencies may change responses towards organic products, so producers and brand managers should fully consider how the interactive effects between their product portfolios, use of the organic label, and retail partners may influence consumers' evaluations of their products.

\section{2 Limitations}

Some limitations of our research yield fruitful opportunities for future research in this area. First, our examination was limited to two retail outlets, Walmart and Target, which are retail brands that exemplify functional and hedonic characteristics, respectively. However, it would be ideal to examine the impact of a variety of additional retailers (e.g., Whole Foods, Aldi, etc.) to replicate and extend our findings. For example, one important way in which our findings could be extended is by examining other meaningful dimensions on which retailers may vary (e.g., on the basis of size - big box versus local retailer or brand personality - sophisticated versus sincere brands). 
Second, we examined virtue and vice products using a single exemplar of each category. Future research could extend our findings in at least two ways. First, researchers could examine a variety of additional products to better understand the significance and generalizability of our results. Second, dimensions other than vice/virtue should be examined to better understand the impact of contextual factors on consumers' responses to organic labeling. For example, do consumers' perceptions and intentions vary depending upon whether food is frozen versus fresh, regular priced or on sale? Food retailers would benefit significantly from these types of insights.

Thirdly, we did not ask respondents about their preferences for strawberries and chocolate cookies in general. If a consumer does not like to eat strawberries (or is allergic), s/he may not care about them being organic or not. This may change the patterns of effect for taste and likelihood of purchase. That being said, even if a respondent does not like or is allergic to strawberries, they should still be able to make evaluations about the perceived nutrition, safety, and cost of the product. Random assignment of participants to the different experimental conditions should ensure that people who had allergies, etc. would be equally distributed amongst the categories and because our primary focus was interaction effects, the preferences of a given individual should be balanced out; however, future research should assess these preferences.

Finally, as is the case with all experimental data, future research examining these effects should be conducted to examine product and brand evaluations and purchase behaviors in a more natural setting (e.g., in an actual store). In our online experiment, all evaluations were hypothetical - a common weakness in many consumer preference studies - so moving to a more realistic setting could help to alleviate concerns over hypothetical bias. Further, since even our simple manipulation provides interesting differences, the full environment of a store may increase those differences, or may offer additional moderating variables that help attenuate some of the findings we report. 


\section{Conclusion}

We contribute to the literature on organic food labeling by examining important, yet underresearched, contextual factors in which the organic purchase takes place. Specifically, we examine the product type (virtue vs. vice) as well as the type of retail outlet context. Our findings suggest that these factors have significant independent and interactive effects on consumers' product and brand perceptions and behavioral intentions towards products labeled organic. Specifically, we find "halo" effects of organic-labeled products (perceived healthiness and safety) and brands (brand attitudes and trust), but - potentially because of a lack of perception of difference in taste, coupled with an increased perception of price (organic brands were perceived as no better tasting, but more expensive) - this effect did not contribute to a higher likelihood of purchase. Additionally, we observed that organic labeling provides differential advantages for virtue and vice products - the organic virtue product had better expected taste and organic vice product had higher expected nutrition. Finally, retail outlets exert important moderating effects on product and brand evaluations. Specifically, retailers like Target may be better outlets for promoting an organic vice product whereas an organic virtue product may receive more of an organic 'lift' at retailers like Walmart. 
Acknowledgements

This research project was funded by USDA NIFA \#ILLU-470-356. 


\section{References:}

Aaker, David A. 1991. Managing Brand Equity, New York: Free Press.

Abrams, Katie M., Courtney A. Meyers, and Tracy A. Irani. 2010. "Naturally Confused: Consumers' Perceptions of All-Natural and Organic Pork Products," Agricultural and Human Values, 27:365-374.

Alba, Joseph W., J. Wesley Hutchinson, and John G. Lynch. 1991. "Memory and Decision Making," in Thomas S. Robertson and Harold H. Kassarjian (Eds), Handbook of Consumer Behavior, pp.1-49.

Asp, Elaine H. 1999. "Factors Affecting Food Decisions Made by Individual Consumers,” Food Policy, 24:287-294.

Baker, Julie, Michael Levy, and Dhruv Grewal. 1992. “An Experimental Approach to Making Retail Store Environmental Decisions," Journal of Retailing, 68(4):445-460.

Batte, Marvin T., Neal H. Hooker, Timothy C. Haab, and Jeremy Beaverson. 2007. "Putting Their Money Where Their Mouths Are: Consumer Willingness to Pay for Multi-ingredient, Processed Organic Food Products," Food Policy, 32:145-159.

Boyle, Katherine. 2012. "Wal-Mart, Target Battle But Have Much in Common," The Washington Post, October 23, http://www.washingtonpost.com/lifestyle/style/2012/10/23/66b97b8e17d0-11e2-9855-71f2b202721b_story.html.

Buhrmester, M., T. Kwang, and S.D. Gosling. 2011. “Amazon's Mechanical Turk: A New Source of Inexpensive, Yet High-Quality, Data?” Perspectives on Psychological Science, 6(1):3-5. Chaurdhuri, Arjun, and Morris B. Holbrook. 2001. "The Chain Effect from Brand Trust and Brand Affect to Brand Performance: The Role of Brand Loyalty," Journal of Marketing, 65(2):8193.

Childers, Terry L., Christopher L. Carr, Joann Peck, and Stephen Carson. 2001. "Hedonic and Utilitarian Motivations for Online Retail Shopping Behavior.” Journal of Retailing, 77(4):511-535.

Conner, David, and Ralph Christy. 2004. "The Organic Label: How to Reconcile its Meaning with Consumer Preferences," Journal of Food Distribution Research, 35(1):40-43.

Dodds, William B., Kent B. Monroe, and Dhruv Grewal. 1991. "Effects of Price, Brand, and Store Information on Buyers' Product Evaluations," Journal of Marketing Research, 28(3):307319. 
Durham, Christopher. 2014. “Aldi Launches SimplyNature.” My Private Brand, January 6, http://mypbrand.com/2014/01/06/aldi-launches-simply-nature/.

Economic Research Service (ERS). "Organic Market Overview.” United States Department of Agriculture. http://www.ers.usda.gov/topics/natural-resources-environment/organicagriculture/organic-market-overview.aspX\#.U8VaZ_ldXzg.

eMarketer. 2014. "Retail Remains Ad Spending Leader." eMarketer, April 16, http://www.emarketer.com/Article/Retail-Remains-Ad-Spending-Leader/1011367.

Ewoldt, John. 2013. “Aldi Jumps on the Organic Bandwagon.” Star Tribune, January 29, http://www.startribune.com/business/188943181.html.

Gardner, Meryl Paula. 1985. "Does Attitude Toward the Ad Affect Brand Attitude Under a Brand Evaluation Set?" Journal of Marketing Research, 22(2):192-198.

Gil, J.M., A. Gracia, and M. Sanchez. 2000. "Market Segmentation and Willingness to Pay for Organic Products in Spain," International Food and Agribusiness Management Review, 3:207-226.

Gilyard, Burl. 2015. "Why the Grocery Business is Now Retail's Hottest Niche." MinnPost, February 2, https://www.minnpost.com/twin-cities-business/2015/02/why-grocery-businessnow-retails-hottest-niche.

Goodman, Joseph K., Cynthia E. Cryder, and Amar Cheema. 2013. "Data collection in a flat world: The strengths and weaknesses of Mechanical Turk samples," Journal of Behavioral Decision Making, 26(3): 213-224.

Greenaway, Twilight. 2014. “Organic Checkoff: Is It What's for Dinner?” Civil Eats, June 26, http://civileats.com/2014/06/26/organic-checkoff-is-it-whats-fordinner/?utm_source=dlvr.it\&utm_medium=twitter\&utm_campaign=organic-checkoff-is-itwhats-for-dinner.

Grgurich, John. 2012. "Why Your Organic Food Isn't as Organic as It Used to Be." Daily Finance, July 11, http://www.dailyfinance.com/2012/07/11/why-your-organic-food-isnt-as-organicas-it-used-to-be/.

Harris, Elizabeth A., and Stephanie Strom. 2014. "Walmart to Sell Organic Food, Undercutting Big Brands." The New York Times, April 10, http://www.nytimes.com/2014/04/10/business/walmart-to-offer-organic-line-of-food-at-cutrate-prices.html. 
Henryks, Joanna, and David Pearson. 2011. "Retail Outlets: Nurturing Organic Food Consumers." Organic Agriculture, 1:247-259.

Hughner, Renee Shaw, Pierre McDonagh, Andrea Prothero, Clifford J. Shultz II, and Julie Stanton. 2007. "Who Are Organic Food Consumers? A Compilation and Review of Why People Purchase Organic Food," Journal of Consumer Behavior, 6:94-110.

Kniazeva, Maria, and Alladi Venkatesh. 2007. "Food for Thought: A Study of Food Consumption in Postmodern US Culture.” Journal of Consumer Behavior, 6:419-435.

Latacz-Lohmann, Uwe, and Carolyn Foster. 1997. 'From 'Niche' to 'Mainstream' - Strategies for Marketing Organic Food in Germany and the UK.” British Food Journal, 99(8):275-282.

Lee, Dongdae, and Michael R. Hyman. 2008. "Hedonic/Functional Congruity between Stores and Private Label Brands," The Journal of Marketing Theory and Practice, 16(3):219-232.

Lee, Mary. 2013. "Creating Equitable Food Environments: The Importance of Accessible, Affordable, Healthy Food for All.” Los Angeles Food Policy Council, October 30, http://goodfoodla.org/2013/10/30/creating-equitable-food-environments-the-importance-ofaccessible-affordable-healthy-food-for-all/.

Lee, Wan-chen Jenny, Mitsuru Shimizu, Kevin M. Kniffin, Brian Wansink. 2013. "You Taste What You See: Do Organic Labels Bias Taste Perceptions?” Food Quality and Preference, 29:3339.

Machleit, Karen A., and Dale Wilson. 1988. "Emotional Feelings and Attitude toward the Advertisement: The Roles of Brand Familiarity and Repetition," Journal of Advertising, 17(3):27-35.

Matzler, Kurt, Sonja Grabner-Krauter, and Sonja Bidmon. 2008. "Risk Aversion and Brand Loyalty: The Mediating Role of Brand Trust and Brand Affect," Journal of Product and Brand Management, 17(3):154-162.

Mitchell, Andrew A. 1986. "The Effect of Verbal and Visual Components of Advertisements on Brand Attitudes and Attitude Toward the Advertisement," Journal of Consumer Research, 13(1):12-24.

Nelson, Phillip. 1970. "Information and Consumer Behavior," Journal of Political Economy, 78(2):311-329.

Ngobo, Paul Valentin. 2011. "What Drives Household Choice of Organic Products in Grocery Stores?” Journal of Retailing, 87(1):90-100. 
Ngobo, Paul Valentin, and Sylvie Jean. 2012. "Does Store Image Influence Demand for Organic Store Brands?” Journal of Retailing and Consumer Services, 19:621-628.

O’Conner, Clare. 2014. “Are Grocery Stores Doomed? Study Shows More Shoppers Buying Food at Target, Walmart, Pharmacies." Forbes, Feb. 18, http://www.forbes.com/sites/clareoconnor/2014/02/18/are-grocery-stores-doomed-studyshows-more-shoppers-buying-food-at-target-walmart-pharmacies/.

Olesen, Ingrid, Frode Alfnes, Mia Bensze Rora, Kari Kolstad. 2010. 'Eliciting Consumers' Willingness to Pay for Organic and Welfare-Labelled Salmon in a Non-Hypothetical Choice Experiment," Livestock Science, 127:218-226.

Raghunathan, Rajagopal, Rebecca Walker Naylor, and Wayne D. Hoyer. 2006. "The Unhealthy=Tasty Intuition and Its Effects on Taste Inferences, Enjoyment, and Choice of Food Products." Journal of Marketing, 70(4):170-184.

Rao, Akshay R., and Kent B. Monroe. 1988, “The Modernizing Effect of Prior Knowledge on Cue Utilization in Product Evaluations," Journal of Consumer Research, 15:253-264.

Roitner-Schobesberger, Birgit, Ika Darnhofer, Suthichai Somsook, and Christian R. Vogl. 2008. "Consumer Perceptions of Organic Foods in Bangkok, Thailand," Food Policy, 33:112-121.

Schaefer, Michael, Harald Berens, Hans-Jochen Heinze, and Michael Rotte. 2006. "Neural Correlates of Culturally Familiar Brands of Car Manufacturers," NeuroImage, 31(2):861865.

Schuldt, Jonathon P., and Mary Hannahan. 2013. "When Good Deeds Leave a Bad Taste. Negative Inferences from Ethical Food Claims," Appetite, 62:76-83.

Schuldt, Jonathon P., and Norbert Schwarz. 2010. "The 'Organic' Path to Obesity? Organic Claims Influence Calorie Judgments and Exercise Recommendations," Judgment and Decision Making, 5(3):144-150.

Simons, Daniel J. and Christopher Chabris. 2012. "Common (Mis) Beliefs about Memory: A Replication and Comparison of Telephone and Mechanical Turk Survey Methods," PLoS One, 7(12): e51876.

Target. 2012. "Target Remodels 90 Stores to Expand Fresh Food Selection.” Target.com, April 24, http://pressroom.target.com/news/target-remodels-90-stores-to-expand-232456. 
Target. 2014. "Target 2014 Annual Report.” Target.com, https://corporate.target.com/_media/TargetCorp/annualreports/2014/pdf/Target-2014Annual-Report.pdf?ext=.pdf.

Tuttle, Brad. 2013. "The Rise of the Swanky No-Name Brand.” Time, June 11, http://business.time.com/2013/06/11/the-rise-of-the-swanky-no-name-brand/.

United States Department of Agriculture (USDAa). 2011. "What is Organic?" Agricultural Marketing Service, http://www.ams.usda.gov/AMSv1.0/getfile?dDocName=STELPRDC5103286. van der Veen, Marijke. 2003. “When is Food a Luxury?” World Archaeology, 34(3):405-427. van Doorn, Jenny, and Peter C. Verhoef. 2011. "Willingness to Pay for Organic Products: Differences Between Virtue and Vice Foods," International Journal of Research in Marketing, 28:167-180.

Walmart. 2014. "Walmart 2014 Annual Report.” Walmart.com, http://stock.walmart.com/files/doc_financials/2014/Annual/2014-annual-report.pdf.

Wertenbroch, Klaus. 1998. "Consumption Self-Control by Rationing Purchase Quantities of Virtue and Vice," Marketing Science, 17(4):317-337.

Wong, Venessa. 2014. "Gluten Free! Natural! Many Food Promises Won't Fetch Premium Prices." Businessweek, http://www.businessweek.com/articles/2014-01-07/gluten-free-natural-manyfood-promises-wont-fetch-premium-prices.

Worstall, Tim. 2014. "Maybe Walmart Has Just Killed the Organic Food Market." Forbes, April 10, http://www.forbes.com/sites/timworstall/2014/04/10/maybe-walmart-has-just-killed-theorganic-food-market/.

Yiridoe, Emmanuel K., Samuel Bonti-Ankomah, and Ralph C. Martin. 2005. "Comparison of Consumer Perceptions and Preference Toward Organic versus Conventionally Produced Foods: A Review and Update of the Literature," Renewable Agriculture and Food Systems, 20(4):193-205.

Zwiebach, Elliot. 2009. "Target to Expand P-Fresh to 350 Stores in 2010." Supermarket News, November 18, http://supermarketnews.com/retail-amp-financial/target-expand-p-fresh-350stores-2010. 


\section{Figure Captions:}

Figure 1. Sample Product Stimuli (Panel A: Non-Organic Strawberries, Walmart Condition; Panel B: Organic Chocolate Sandwich Cookies, Target Condition)

Figure 2. Two-Way Interaction between Organic Labeling and Product Type on Expected Taste

Figure 3. Three-Way Interaction on Expected Taste

Figure 4. Two-Way Interaction between Organic Labeling and Product Type on Nutrition

Figure 5. Two-Way Interaction between Organic Labeling and Product Type on Expected Product Cost

Figure 6. Three-Way Interaction on Trust towards Cam's Brand 
Table 1. Characteristics of Study Participants $(N=605)$

\begin{tabular}{|c|c|c|}
\hline Variable & Definition & $\begin{array}{c}\text { Sample } \\
\text { Proportion }\end{array}$ \\
\hline \multirow[t]{2}{*}{ Gender } & Female & $37.2 \%$ \\
\hline & Male & $62.8 \%$ \\
\hline \multirow[t]{4}{*}{ Education } & Some High School or High School Diploma/GED & $11.1 \%$ \\
\hline & Some College & $36.0 \%$ \\
\hline & Associates or Technical Degree & $9.1 \%$ \\
\hline & Bachelor's Degree or Higher & $43.8 \%$ \\
\hline \multirow[t]{4}{*}{ Age } & 18 to 24 years old & $31.2 \%$ \\
\hline & 25 to 34 years old & $45.0 \%$ \\
\hline & 35 to 44 years old & $12.2 \%$ \\
\hline & 45 years or older & $11.6 \%$ \\
\hline \multirow[t]{3}{*}{ Income } & Annual household income is less than $\$ 50,000$ & $60.8 \%$ \\
\hline & Annual household income is between $\$ 50,000$ and $\$ 99,999$ & $30.6 \%$ \\
\hline & Annual household income is $\$ 100,000$ or greater & $8.6 \%$ \\
\hline \multirow[t]{4}{*}{ Geographic Region } & Resides in Northeastern region of U.S. & $23.9 \%$ \\
\hline & Resides in Midwestern region of U.S. & $24.1 \%$ \\
\hline & Resides in Southern region of U.S. & $31.2 \%$ \\
\hline & Resides in Western region of U.S. & $20.8 \%$ \\
\hline \multirow[t]{2}{*}{ Primary Shopper } & Yes, primary shopper in household & $73.2 \%$ \\
\hline & No, not primary shopper in household & $26.8 \%$ \\
\hline \multirow[t]{3}{*}{ Organic Buyer } & Purchases organic food always or most of the time & $10.6 \%$ \\
\hline & Purchases organic food sometimes & $42.1 \%$ \\
\hline & Purchases organic food rarely or never & $47.3 \%$ \\
\hline \multirow[t]{6}{*}{ Shopping Location } & Primarily shops at Local/Regional Supermarkets & $55.9 \%$ \\
\hline & Primarily shops at Walmart & $20.1 \%$ \\
\hline & Primarily shops at Target & $4.8 \%$ \\
\hline & Primarily shops at Bulk Merchandiser & $6.6 \%$ \\
\hline & Primarily shops at Specialty Store & $6.8 \%$ \\
\hline & Primarily shops at Other Type of Store & $5.9 \%$ \\
\hline
\end{tabular}


Figure 1a

Available At:

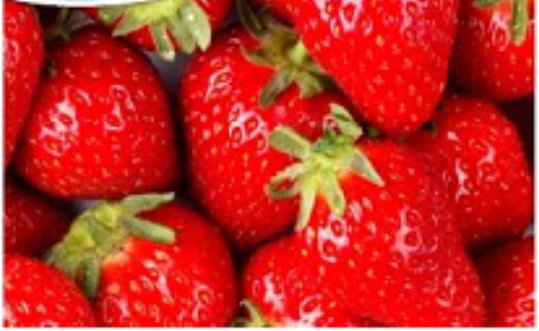

Walmart : 


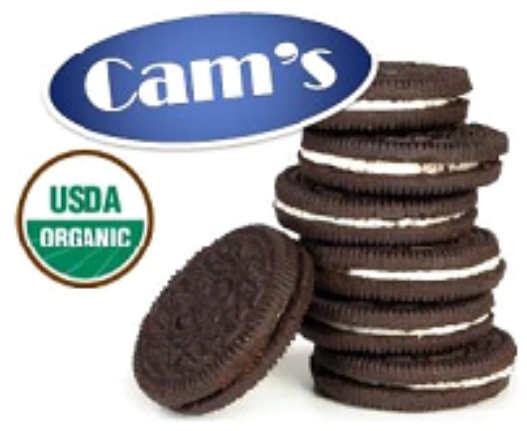

Available At:

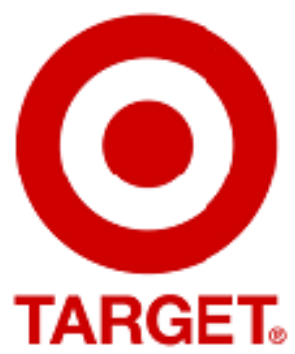

Figure 1b 


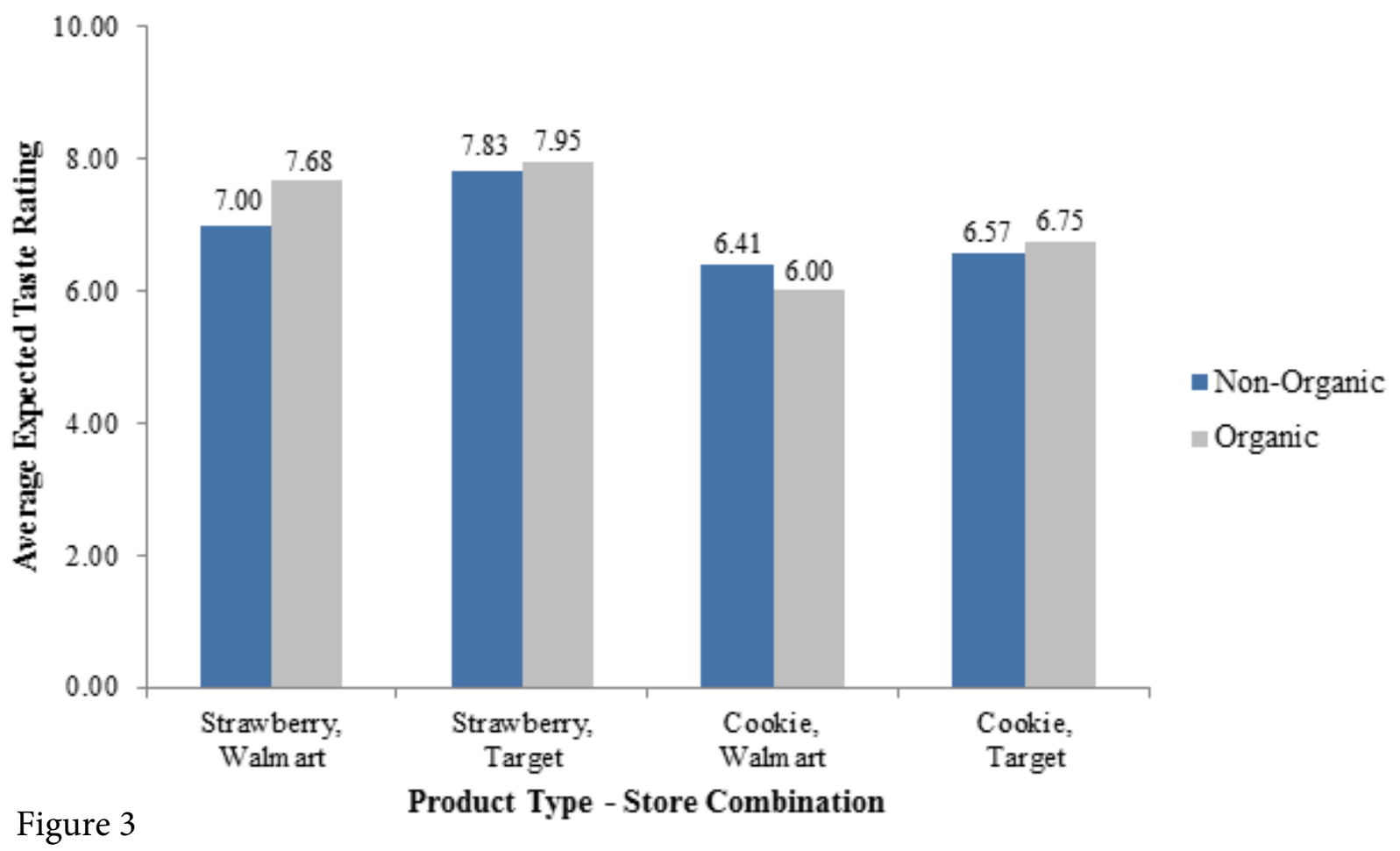




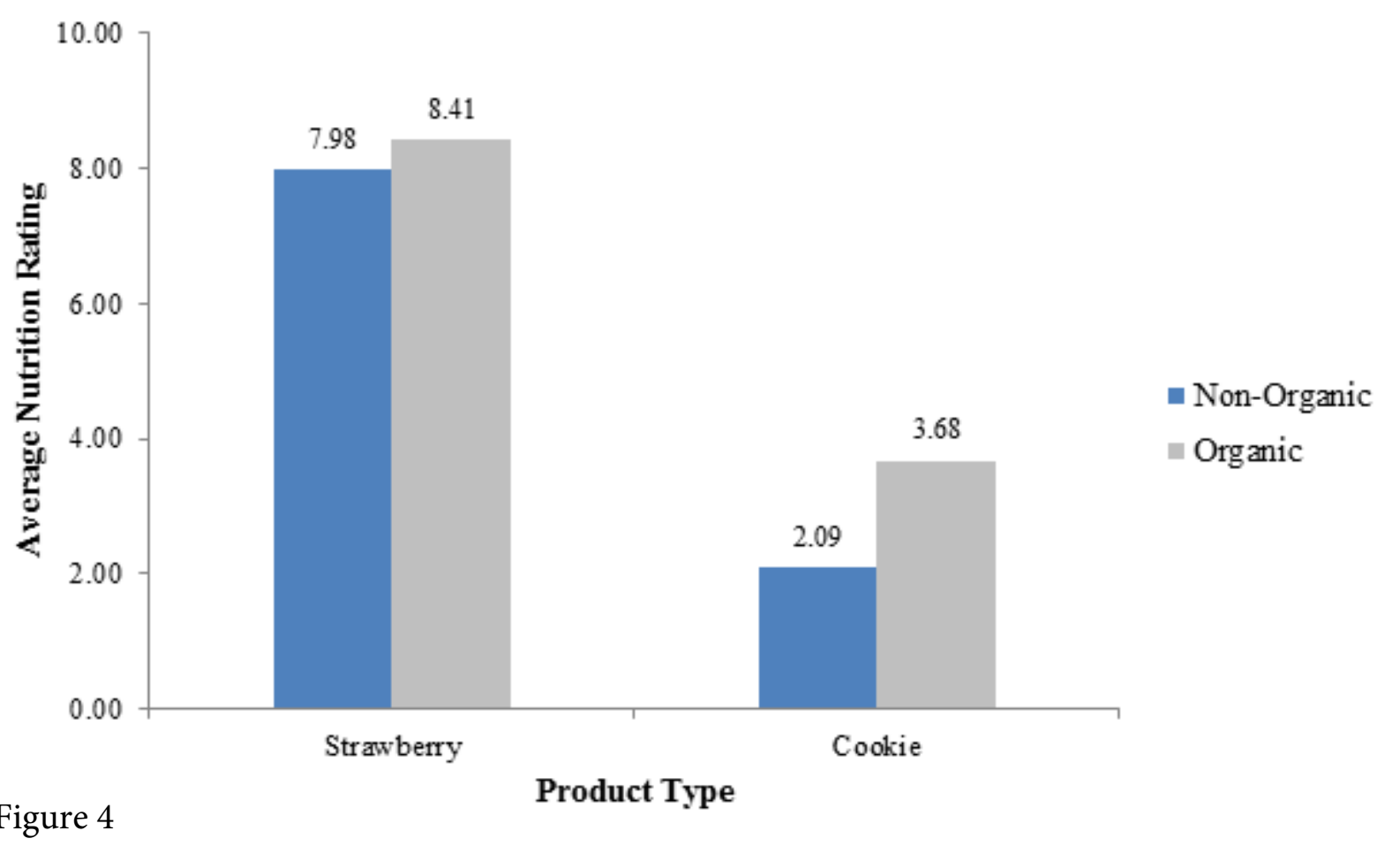




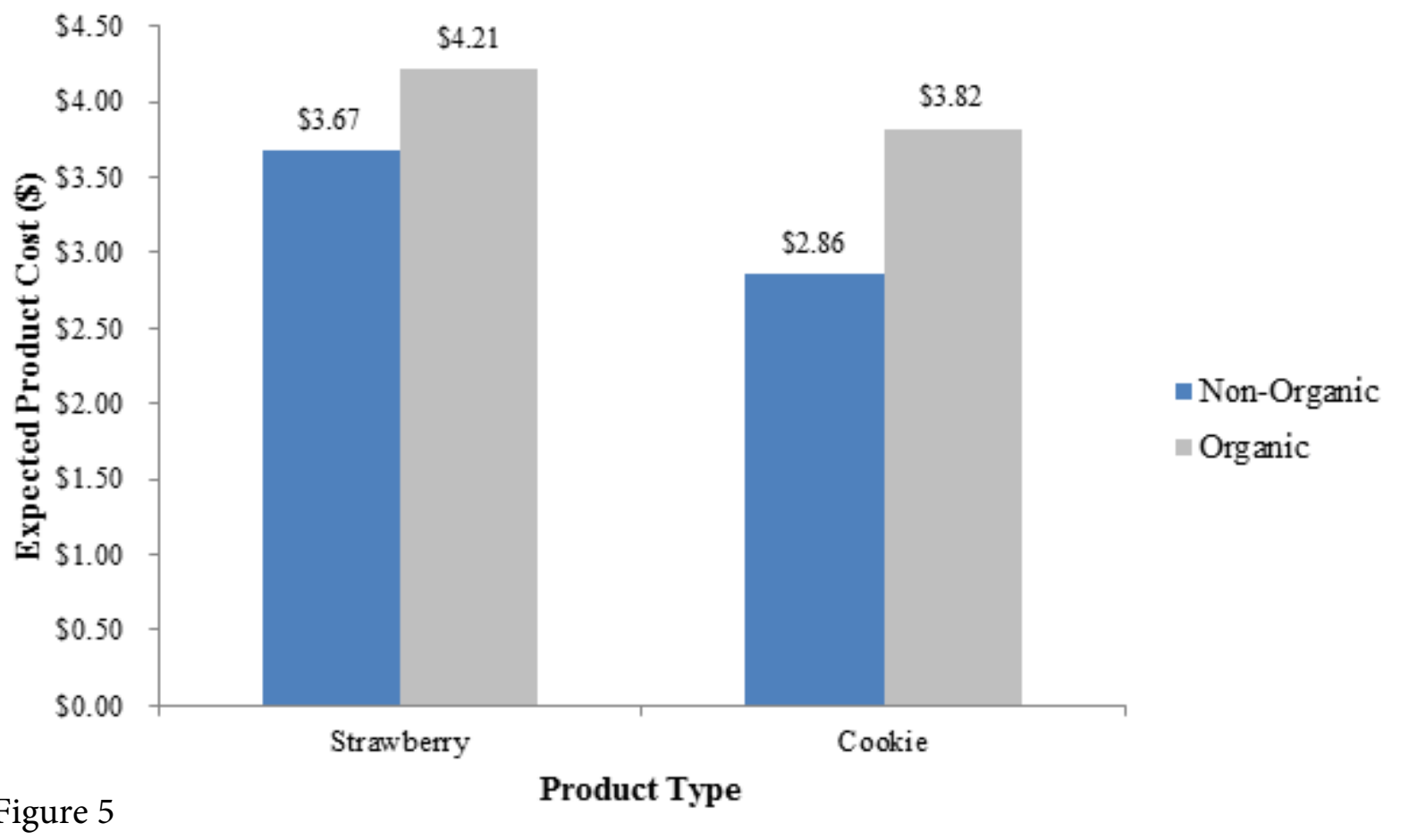




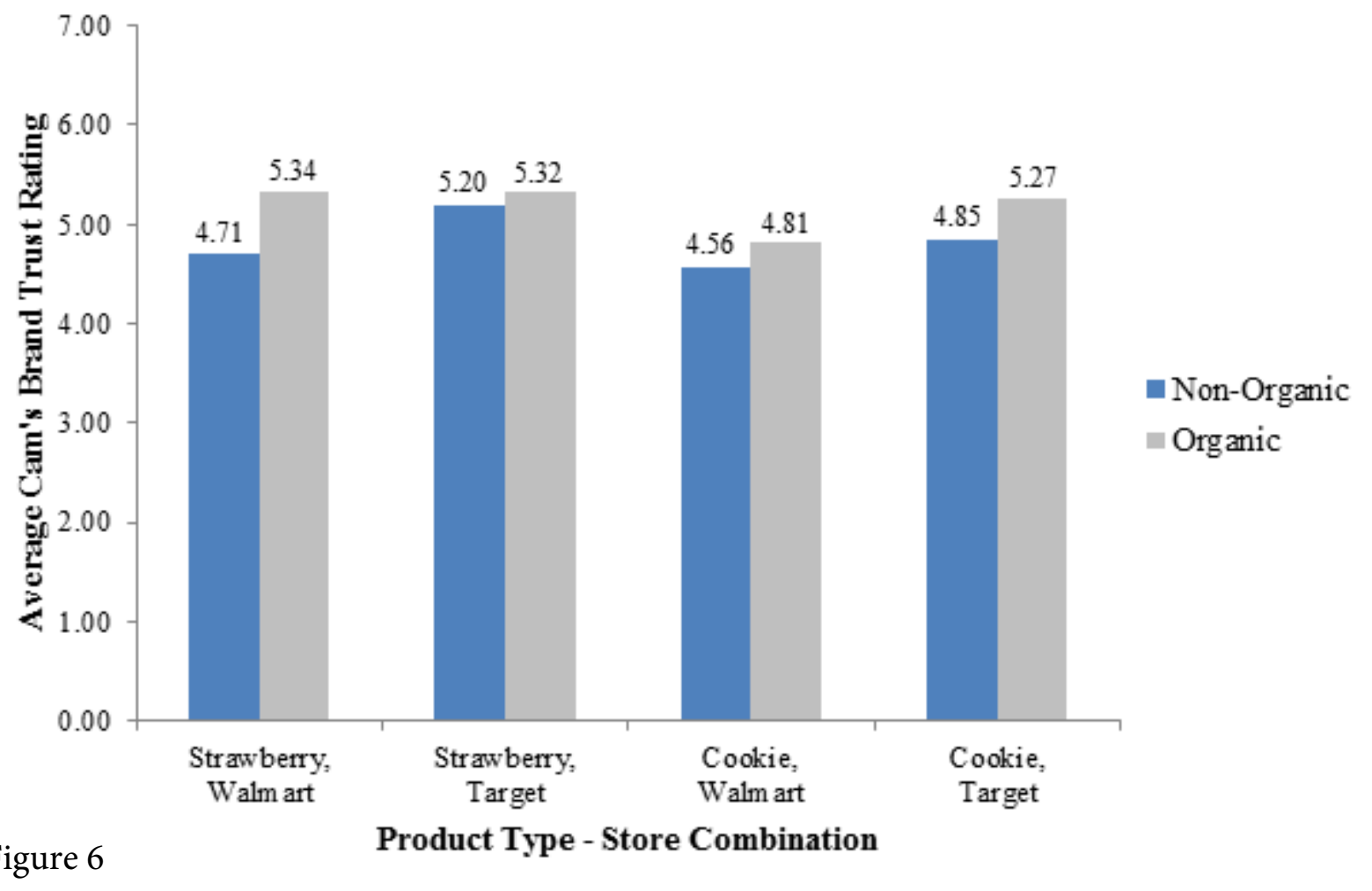

